\title{
Level of Ischemia Modified Albumin in the Sera of Families with a Case of Rheumatic Fever and/or Rheumatic Heart Diseases
}

\author{
EBTSAM A. ATTIA, M.Sc.*; SALAH A. SHOHEIB, M.D.*; WALID A. EL-SHEHABY, M.D.*; \\ NAHED M. ELWAN, M.D.**; AHMED SHABANA, M.D.* and AHMED S. SHOHEIB, M.D.*** \\ The Departments of Pediatrics*, Clinical Pathology** and Cardiology***, Faculty of Medicine, Tanta University
}

\begin{abstract}
Background: Ischaemia-modified albumin (IMA), a novel biochemical marker for tissue ischaemia, was found to be associated with oxidative stress.

Aim of Study: Was to measure the level of ischemia modified albumin in sera of families with a case of rheumatic fever/rheumatic heart diseases whatever their presentation.

Patients and Methods: This study was done on 10 families of RF including 10 index cases, 10 mothers and 10 fathers and 20 siblings (total $n=50$ ) attending the $R F$ clinic of pediatric department, All Patients had a full sheet, complete clinical examination and routine laboratory investigations (ESR, CRP, Blood group, CBC, ASOT and IMA) and ECHO. Control group, comprised 10 families including 10 mothers, 10 fathers and 30 siblings (total $\mathrm{n}=50$ ).

Results: There was significant increase of IMA in between [cases of typical group as compared to control cases $p\left(<0.001^{*}\right)$ - cases of atypical group as compared to control cases $p(0.001 *)$ - cases of atypical group as compared to their siblings $p\left(<0.001^{*}\right)$, there was no significant increase of IMA in between (cases of typical group as compared to their siblings $p(0.071)$ - siblings of atypical group as compared to control siblings $p(0.182)]$.

Conclusion: Our study concluded that serum IMA level and ASOT increased in children with ARF/RHD as well as their siblings which facilitate early detection and management of RF in siblings of a case of RF depending on positive family history and elevating anti-streptococcal antibodies and serum Ischemia modified albumin.
\end{abstract}

Key Words: Ischemia modified albumin - Acute rheumatic fever-Rheumatic heart diseases.

\section{Introduction}

ACUTE rheumatic fever (ARF) is a post infectious, nonsuppurative sequelae of pharyngeal infection with Group A 33 hemolytic Streptococcus (GABHS). Of the associated symptoms, only damage to the valve tissue within the heart, or rheumatic heart disease (RHD), can become a chronic condition

Correspondence to: Dr. Ebtsam A. Attia, The Department of Pediatrics, Faculty of Medicine, Tanta University leading to congestive heart failure, strokes, endocarditis, and death [1].

ARF is characterized by nonsuppurative inflammatory lesions of the joints, heart, subcutaneous tissue, and central nervous system [2]. The overall attack rate after streptococcal pharyngitis varies between $0.3-3 \%$, but certain genetically predisposed individuals, comprising perhaps $3 \%-6 \%$ of the population, account for those who develop rheumatic fever [1]

Rheumatic fever manifests as various signs and symptoms that may occur alone or in various combinations: Sore throat, polyarthritis, carditis, sydenham chorea, erythema marginatum and subcutaneous nodules. Other symptoms may include fever, abdominal pain, arthralgia, malaise, and epistaxis [3]

If supported by evidence of preceding group A streptococcal infection, the presence of two major manifestations or one major and two minor manifestations indicates a high probability of ARF. Failure to fulfill the Jones criteria makes the diagnosis unlikely but not impossible. Clinical judgment is required. The World Health Organization (WHO) follows the Jones criteria for the diagnosis of ARF, but possible recurrences require only two minor criteria plus evidence of recent streptococcal infection [1]

Jones criteria include major criteria as follows: Carditis (based on clinical criteria), polyarthritis, chorea, erythema marginatum, subcutaneous nodules. Minor criteria are as follows: Arthralgia, fever, elevated ESR or CRP level and prolonged PR interval [4]

As regards diagnosis there is no single specific laboratory test can confirm the diagnosis of ARF. 
Throat culture remains the criterion standard for confirmation of group A streptococcal infection, Antibody titer tests used include anti streptolysin O titre (ASO) test. Acute-phase reactants, the erythrocyte sedimentation rate (ESR), and Creactive protein levels (CRP) are usually elevated at the onset of ARF and serve as a minor manifestation in the Jones criteria. These tests are nonspecific, but they may be useful in monitoring disease activity [5].

Ischaemia-modified albumin is a new marker for tissue ischaemia. It has been proposed that reactive oxygen species generated during ischaemia results in ischaemia-modified albumin formation. Ischaemia-modified albumin is accepted as a marker of oxidative stress. Recently, elevated ischaemiamodified albumin levels have been reported in various clinical conditions such as ischaemia, inflammation, and oxidative stress. Furthermore, increased oxidative stress has been shown in acute rheumatic fever and heart valve disease [6].

\section{Aim of work:}

To measure the level of ischemia modified albumin in sera of families with a case of rheumatic fever/rheumatic heart diseases whatever was their presentation. Moreover, the level of ischemia modified albumin gave us an idea about the state of affection of the heart valves that helped us in treatment protocol.

\section{Subjects and Methods}

This study was carried out at the Cardiac Unit, Pediatric Department, Tanta University Hospital from June 2017 - April 2018.

This study was done on 10 families of rheumatic fever (RF) cases including 10 index cases, 10 mothers and 10 fathers and 20 siblings (total $n=50$ ) attending the RF clinic of pediatric department, Tanta University Hospitals. Control group, comprised 10 families including 10 mothers, 10 fathers and 30 siblings (total $n=50$ ).

\section{Classification of patient and control individuals:}

1- 5 families of typical presentation of rheumatic fever/rheumatic heart disease in any member including childern aged from 5-15 years.

2- 5 families of atypical presentation of rheumatic fever in any member including childern aged from 5-15 years.

3- 10 families who have no history of acute rheumatic fever nor on long acting penicillin was enrolled in the study as a control group.

\section{Results}

T\&A: Comparison between Typical and Atypical group.

T\&C: Comparison between Typical and Control group.

A\&C: Comparison between Atypical and Control group.

Table (1): Age distribution among the studied group.

\begin{tabular}{llllll}
\hline & \multicolumn{3}{c}{ Groups } & \multicolumn{2}{c}{ ANOVA } \\
\cline { 2 - 6 } Age & Typical & Atypical & Controls & F & $\begin{array}{c}p \text { - } \\
\text { value }\end{array}$ \\
\cline { 2 - 6 } Case: & & & & & \\
$\quad$ Range & $10-13$ & $9-15$ & $6-15$ & 0.488 & 0.622 \\
Mean \pm SD & $11.400 \pm$ & $11.600 \pm$ & $10.500 \pm$ & & \\
& 1.140 & 2.191 & 2.677 & & \\
Sibling: & & & & & \\
$\quad$ Range & $5-16$ & $5-18$ & $3-13$ & 2.424 & 0.102 \\
Mean \pm SD & $8.600 \pm$ & $10.400 \pm$ & $7.300 \pm$ & & \\
& 4.195 & 4.766 & 2.618 & & \\
$t$-Test: & & & & & \\
$t$ & 1.441 & 0.528 & & & \\
$p$-value & 0.173 & 0.606 & & & \\
\hline
\end{tabular}

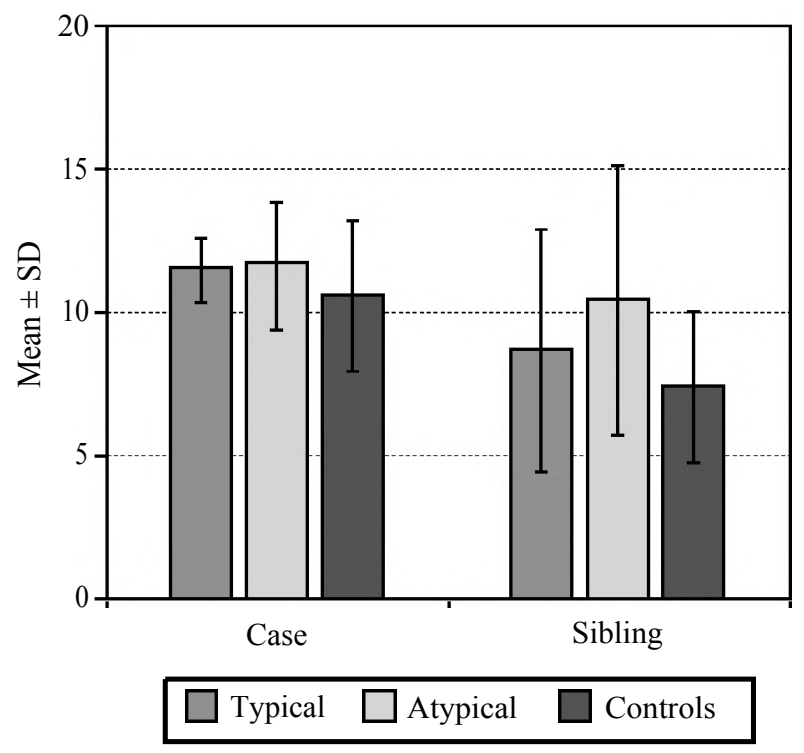

Fig. (1): Age distribution among the studied groups.

Table (1) and Fig. (1) show that there was no significance difference between studied groups as regard the age with mean 11.4 years among cases of typical group and 11.6 years among atypical group. 
Table (2): Comparison of mean ESR (1 st h) among the studied groups.

\begin{tabular}{|c|c|c|c|c|c|c|c|c|}
\hline \multirow{2}{*}{ ESR 1} & \multicolumn{3}{|c|}{ Groups } & \multicolumn{2}{|c|}{ ANOVA } & \multicolumn{3}{|c|}{ TUKEY'S Test } \\
\hline & Typical & Atypical & Controls & $\mathrm{F}$ & $p$-value & $\mathrm{T} \& \mathrm{~A}$ & $\mathrm{~T} \& \mathrm{C}$ & $\mathrm{A} \& \mathrm{C}$ \\
\hline \multicolumn{9}{|l|}{ Case: } \\
\hline Range & $20-70$ & $30-40$ & $3-30$ & 16.75 & $<0.001 *$ & 0.582 & $<0.001 *$ & $0.002 *$ \\
\hline Mean \pm SD & $43.00 \pm 18.57$ & $36.0 \pm 4.18$ & $11.50 \pm 8.16$ & & & & & \\
\hline \multicolumn{9}{|l|}{ Sibling: } \\
\hline Range & $10-40$ & $10-30$ & $3-25$ & 7.154 & $0.002 *$ & $0.041^{*}$ & $0.002 *$ & 0.240 \\
\hline Mean \pm SD & $24.00 \pm 12.42$ & $17.0 \pm 6.32$ & $11.55 \pm 7.08$ & & & & & \\
\hline \multicolumn{9}{|l|}{ t-Test: } \\
\hline$t$ & 2.376 & 6.032 & & & & & & \\
\hline$p$-value & $0.034^{*}$ & $<0.001 *$ & & & & & & \\
\hline
\end{tabular}

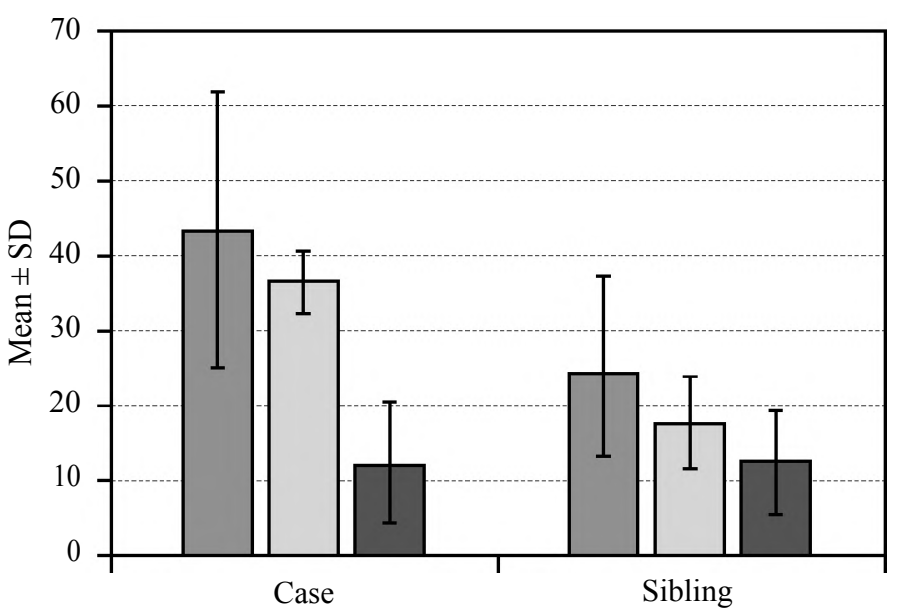

\section{Typical $\square$ Atypical $\square$ Controls}

Fig. (2): Comparison of Mean ESR (1 st h) among the studied groups.
Table (2) and Fig. (2) show that there was significant increase of mean ESR ( $1 \mathrm{st} \mathrm{h})$ in between [cases of typical group as compared to control cases $p\left(<0.001^{*}\right)$ - cases of atypical group as compared to control cases $p(0.002 *)$ cases of typical group as compared to their siblings $p\left(0.034^{*}\right)$ - cases of atypical group as compared to their siblings $p\left(<0.001^{*}\right)$ - siblings of typical group as compared to control siblings $p(0.002 *)$-siblings of typical group as compared to siblings of atypical group $p(0.041 *)]$, there was no significant increase of mean ESR ( $1 \mathrm{st} \mathrm{h})$ in between [cases of typical group as compared to cases of atypical group $p(0.582)$-siblings of atypical group as compared to control siblings $p(0.240)]$.

Table (3): Comparison of IMA level among the studied groups.

\begin{tabular}{|c|c|c|c|c|c|c|c|c|}
\hline \multirow{2}{*}{$\begin{array}{l}\text { IMA } \\
(\mathrm{pg} / \mathrm{ml})\end{array}$} & \multicolumn{3}{|c|}{ Groups } & \multicolumn{2}{|c|}{ ANOVA } & \multicolumn{3}{|c|}{ TUKEY'S Test } \\
\hline & Typical & Atypical & Controls & $\mathrm{F}$ & $p$-value & $\mathrm{T} \& \mathrm{~A}$ & $\mathrm{~T} \& \mathrm{C}$ & $\mathrm{A} \& \mathrm{C}$ \\
\hline \multicolumn{9}{|l|}{ Case: } \\
\hline Range & $215-432$ & $190-220$ & $12-150$ & 32.894 & $<0.001 *$ & $0.031 *$ & $<0.001 *$ & $0.001 *$ \\
\hline Mean \pm SD & $292.40 \pm 82.13$ & $202.00 \pm 13.038$ & $73.400 \pm 43.002$ & & & & & \\
\hline \multicolumn{9}{|l|}{ Sibling: } \\
\hline Range & $80-323$ & $70-130$ & $12-132$ & 20.874 & $<0.001 *$ & $0.001 *$ & $<0.001 *$ & 0.182 \\
\hline Mean \pm SD & $196.20 \pm 92.43$ & $99.200 \pm 19.71$ & $61.500 \pm 37.801$ & & & & & \\
\hline \multicolumn{9}{|l|}{ t-Test: } \\
\hline$t$ & 1.965 & 10.470 & & & & & & \\
\hline$p$-value & 0.071 & $<0.001 *$ & & & & & & \\
\hline
\end{tabular}




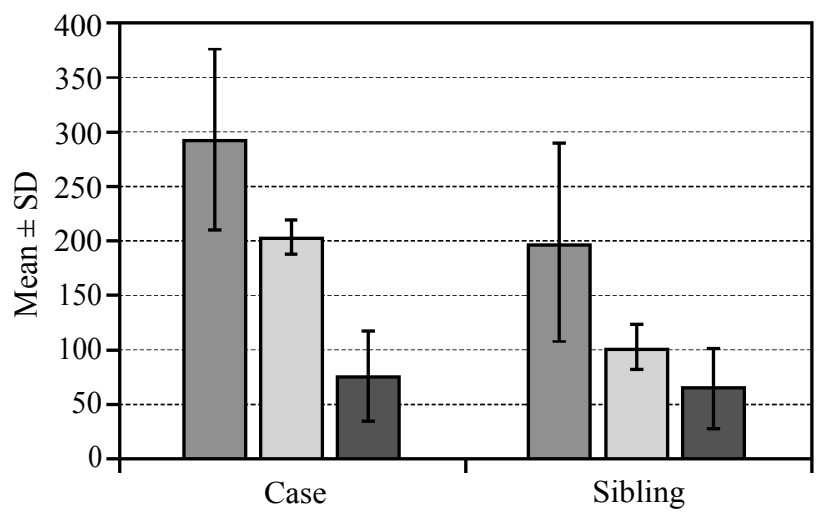

$\square$ Typical $\square$ Atypical $\square$ Controls

Fig. (3): Comparison of IMA Level among the studied group.
Table (3) and Fig. (3) show that there was significant increase of IMA in between [cases of typical group as compared to control cases $p\left(<0.001^{*}\right)$ - cases of atypical group as compared to control cases $p\left(0.001^{*}\right)$ - cases of atypical group as compared to their siblings $p(<0.001 *)$ - cases of typical group as compared to cases of atypical group $p(0.031 *)$ - in siblings of typical group as compared to control siblings $p(<0.001 *)$ - siblings of typical group as compared to siblings of atypical group $p(0.001 *)$ ], there was no significant increase of IMA in between (cases of typical group as compared to their siblings $p(0.071)$ - siblings of atypical group as compared to control siblings $p(0.182)]$.

Table (4): Blood group distribution among the studied groups.

\begin{tabular}{|c|c|c|c|c|c|c|c|c|c|c|}
\hline \multirow{3}{*}{$\begin{array}{l}\text { Blood } \\
\text { group }\end{array}$} & \multicolumn{8}{|c|}{ Groups } & \multirow{2}{*}{\multicolumn{2}{|c|}{ Chi-Square }} \\
\hline & \multicolumn{2}{|c|}{ Typical } & \multicolumn{2}{|c|}{ Atypical } & \multicolumn{2}{|c|}{ Controls } & \multicolumn{2}{|c|}{ Total } & & \\
\hline & $\mathrm{N}$ & $\%$ & $\mathrm{~N}$ & $\%$ & $\mathrm{~N}$ & $\%$ & $\mathrm{~N}$ & $\%$ & $\mathrm{X}^{2}$ & $p$-value \\
\hline \multicolumn{11}{|l|}{ Case: } \\
\hline A+ & 3 & 60.00 & 2 & 40.00 & 2 & 20.00 & 7 & 35.00 & 3.571 & 0.734 \\
\hline $\mathrm{B}+$ & 1 & 20.00 & 2 & 40.00 & 3 & 30.00 & 6 & 30.00 & & \\
\hline $\mathrm{O}+$ & 0 & 0.00 & 0 & 0.00 & 1 & 10.00 & 1 & 5.00 & & \\
\hline $\mathrm{AB}+$ & 1 & 20.00 & 1 & 20.00 & 4 & 40.00 & 6 & 30.00 & & \\
\hline \multicolumn{11}{|l|}{ Sibling: } \\
\hline $\mathrm{A}+$ & 4 & 40.00 & 4 & 40.00 & 5 & 25.00 & 13 & 32.50 & 2.769 & 0.837 \\
\hline $\mathrm{B}+$ & 0 & 0.00 & 0 & 0.00 & 2 & 10.00 & 2 & 5.00 & & \\
\hline $\mathrm{O}+$ & 3 & 30.00 & 3 & 30.00 & 6 & 30.00 & 12 & 30.00 & & \\
\hline $\mathrm{AB}+$ & 3 & 30.00 & 3 & 30.00 & 7 & 35.00 & 13 & 32.50 & & \\
\hline \multicolumn{11}{|l|}{ Chi-Square: } \\
\hline$X^{\frac{1}{2}}$ & \multicolumn{2}{|c|}{3.911} & \multicolumn{2}{|c|}{5.625} & & & & & & \\
\hline$p$-value & \multicolumn{2}{|c|}{0.271} & \multicolumn{2}{|c|}{0.131} & & & & & & \\
\hline
\end{tabular}

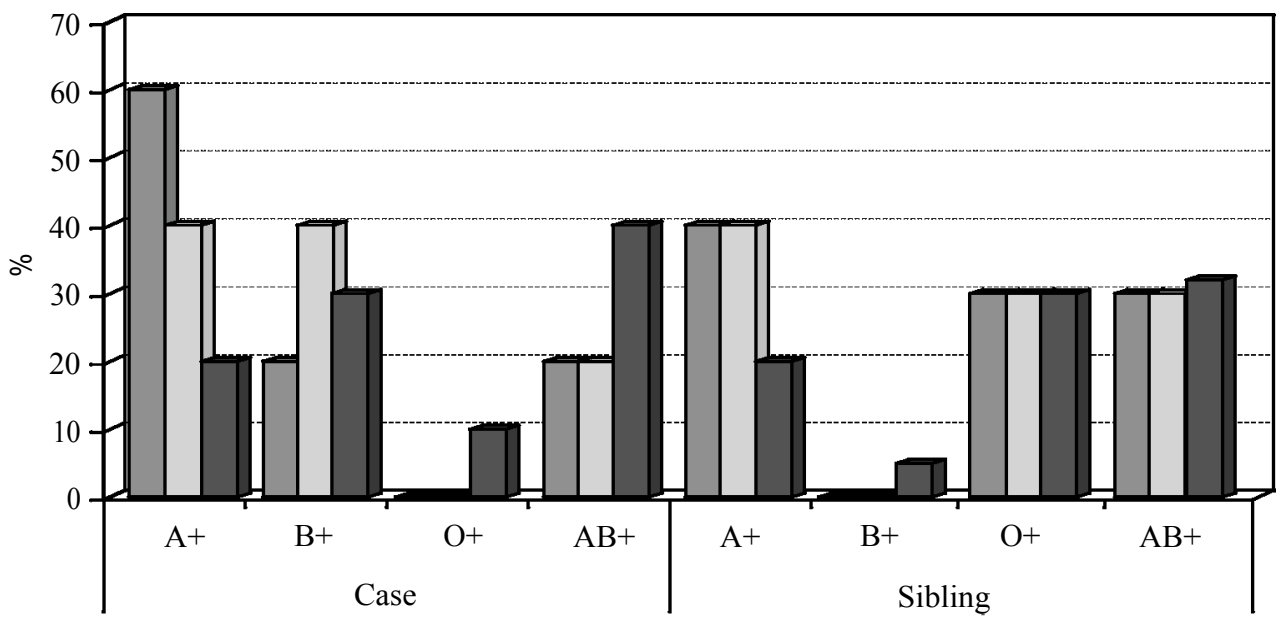

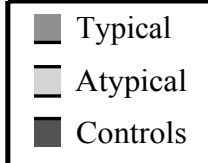

Fig. (4): Blood group distribution among the studied groups. 
Table (4) and Fig. (4) show that A+ blood group was more common in typical cases while
$\mathrm{A}+$ and $\mathrm{B}+$ were more common in studied atypical cases.

Table (5): Comparison of CRP results among the studied groups.

\begin{tabular}{|c|c|c|c|c|c|c|c|c|c|c|}
\hline \multirow{3}{*}{ CRP } & \multicolumn{8}{|c|}{ Groups } & & \\
\hline & \multicolumn{2}{|c|}{ Typical } & \multicolumn{2}{|c|}{ Atypical } & \multicolumn{2}{|c|}{ Controls } & \multicolumn{2}{|c|}{ Total } & \multicolumn{2}{|c|}{ Chi-Square } \\
\hline & $\mathrm{N}$ & $\%$ & $\mathrm{~N}$ & $\%$ & $\mathrm{~N}$ & $\%$ & $\mathrm{~N}$ & $\%$ & $\mathrm{X} 2$ & $p$-value \\
\hline \multicolumn{11}{|l|}{ Case: } \\
\hline Negative & 0 & 0.00 & 0 & 0.00 & 10 & 100.00 & 10 & 50.00 & 20.000 & $<0.001 *$ \\
\hline Positive & 5 & 100.00 & 5 & 100.00 & 0 & 0.00 & 10 & 50.00 & & \\
\hline \multicolumn{11}{|l|}{ Sibling: } \\
\hline Negative & 5 & 50.00 & 5 & 50.00 & 18 & 90.00 & 28 & 70.00 & 7.619 & $0.022 *$ \\
\hline Positive & 5 & 50.00 & 5 & 50.00 & 2 & 10.00 & 12 & 30.00 & & \\
\hline \multicolumn{11}{|l|}{ Chi-Square: } \\
\hline $\mathrm{X} 2$ & \multicolumn{2}{|c|}{5.232} & \multicolumn{2}{|c|}{5.232} & & & & & & \\
\hline$p$-value & \multicolumn{2}{|c|}{$0.022 *$} & \multicolumn{2}{|c|}{$0.022 *$} & & & & & & \\
\hline
\end{tabular}

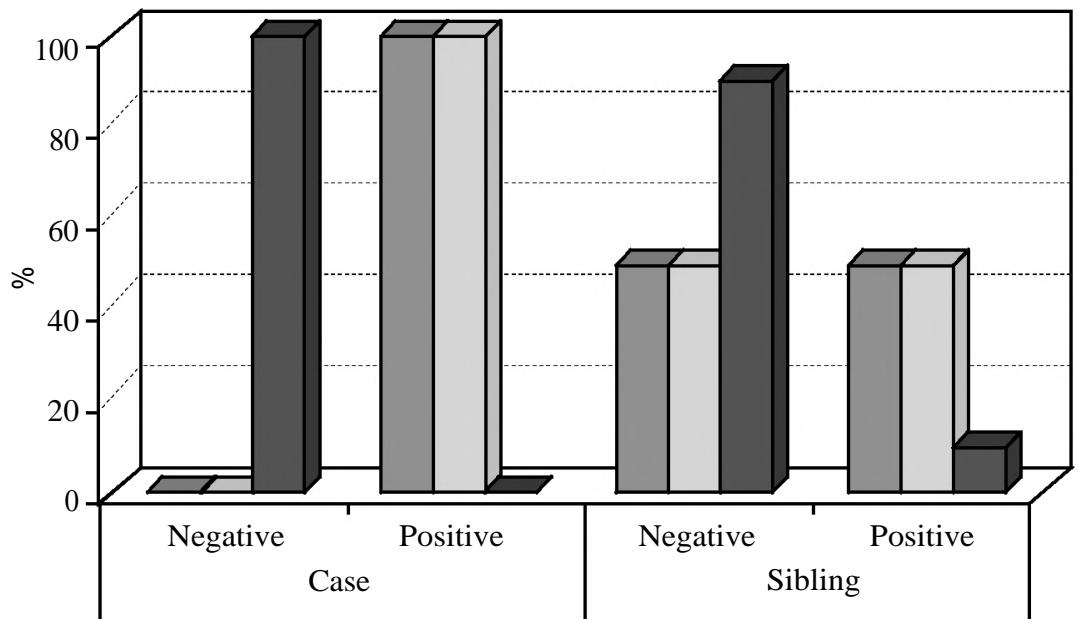

\section{$\square$ Typical \\ Atypical \\ Controls}

Fig. (5): Comparison of CRP results among the studied groups.
Table (5) and Fig. (5) show that there was significant increase of CRP level in patients as compared to controls in the two studied groups with $(p=<$ $\left.0.001^{*}\right)$, and there was significant increase in patients

Table (6): Clinical data of siblings of families.

\begin{tabular}{lcc}
\hline \multirow{2}{*}{ CRP } & \multicolumn{2}{c}{ Sibling of families } \\
\cline { 2 - 3 } & $\mathrm{N}$ & $\%$ \\
\hline Organic lesion & 7 & 35.00 \\
Atypical & 3 & 15.00 \\
Normal & 10 & 50.00 \\
\hline Total & & \\
\hline
\end{tabular}

Table (6) and Fig. (6) show that 10 siblings were normal with percentage $50 \%, 7$ siblings had as compared to their siblings in the two studied groups with $(p=0.022 *)$ also there was significant increase in patient siblings as compared to control siblings with $\left(p=0.022^{*}\right)$ in the two studied groups.
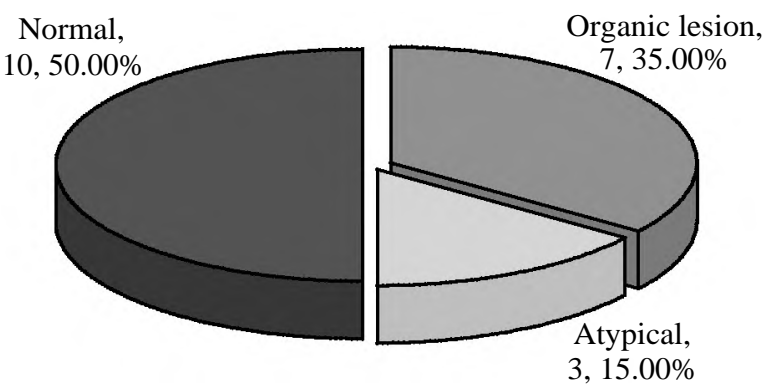

Fig. (6): Clinical data of siblings of families.

atypical presentation with percentage $35 \%$ and 3 had organic lesions with percentage $15 \%$. 


\section{Discussion}

Acute rheumatic fever is an autoimmune inflammatory process that develops as a sequelae of streptococcal infection. ARF has extremely variable manifestations and remains a clinical syndrome for which no specific diagnostic test exists. Persons who have experienced an episode of ARF are predisposed to recurrences following subsequent GAS infections. The most significant complication of ARF is RHD, which usually occurs after repeated bouts of acute illness [7].

To avoid over diagnosis in low-incidence populations and to avoid under diagnosis in high-risk populations, variability in applying diagnostic criteria in low-risk compared with high-risk populations is reasonable [8].

ARF is diagnosed in the presence of two major, or one major and two minor manifestations and must be accompanied by supporting evidence of antecedent GAS infection in the form of positive throat culture or elevated or rising anti-streptolysin titer [9]. Moreover, Shoheib concluded that, ARF may present with three major signs [10].

The aim of this work was to estimate the value of measuring serum ischemia modified albumin in the sera of children of families with a case of RF/RHD.

The present study was done on 10 families of $\mathrm{RF}$ attending the RF clinic of pediatric department, Tanta University Hospitals. Control Group was 10 families free from RF or any systemic diseases.

In the present study, the age of patients ranged from 5-15 years old with mean value of 10 years. Most studies attribute this age of incidence to the repeated sore throat and streptococcal infection in school children [11].

Previous reports have indicated an association between $\mathrm{ABO}$ blood group and RF, but the results differ from one study to another. In the present work, when comparing the results of $\mathrm{ABO}$ blood group of rheumatic patients to that of control, a definite increase in $\mathrm{A}+(50 \%)$ and $\mathrm{B}+(30 \%)$, at expense of $\mathrm{AB}+$ and $\mathrm{O}+$. Group these results are similar to previous study of Shoheib et al., which concluded that both $\mathrm{A}+$ and $\mathrm{B}+$ blood groups were more common in patients than in controls [12]

Our patients showed statistically significant differance between the studied groups compared to control as regard TLC and CRP as they are considered acute-phase reactants which are usually elevated at the onset of ARF and serve as a minor manifestation in the Jones criteria. These tests are nonspecific, but they may be useful in monitoring disease activity) [13]

We found in this work $100 \%$ of rheumatic cases were positive for CRP with significant increase compared with control in both typical and atypical groups ( $p$-value $<0.001 *$ ). We found also $50 \%$ of rheumatic patient siblings were positive for CRP compared with their control $(p$-value $=0.022 *)$.

Similar results were obtained by Rayamajhi et al. in a prospective, cross sectional study over 2 years on 36 children under 14 years with RF and found that elevated CRP in $78 \%$ of patients and this was confirmed by Echocardiography [14]

Our results showed that ESR was significantly elevated in rheumatic patients and sibling groups in both typical and atypical groups compared with the corresponding control. These results may be explained on the basis that elevation of ESR is most commonly associated with infection and extreme elevation of ESR in children may be used as sickness index, but not as screen tool for disease [15].

$\mathrm{RF}$ was the most common disease that causes elevation of ESR. Idress and AL Qahtani reported that children measured and adults in areas where $\mathrm{RF}$ is common, ESR $>60 \mathrm{~mm} / \mathrm{h}$ may favor the diagnosis of RF [16]

Our results showed that there was positive correlation between ASOT and ESR and CRP. In contrast to Ben-Chetrit et al., in a study showed that there was no correlation between ASO serum levels, ESR and CRP [17]

As regard IMA, our study compared patients with controls in both typical and atypical groups and found that there was statistically high significant elevation of IMA in the patient groups as compared to control group in both typical group and atypical group with mean value $(292.400 \mathrm{pg} / \mathrm{ml})$ $(202.000 \mathrm{pg} / \mathrm{ml})$ respectively, with ( $p$-value $<0.001 *)(p$-value $=0.001 *)$ respectively, there was significant increase in patients of atypical group as compared to their siblings with ( $p$-value $<0.001 *)$, there was significant increase in siblings of typical group and control siblings ( $p$-value $<0.001 *)$, also there was significant increase in siblings of typical group and siblings of atypical group ( $p$-value $0.001 *)$.

These results were quite similar to the results of KarataŞ et al., who showed that in a previous study, the serum ischaemia-modified albumin levels of both acute rheumatic carditis and isolated arthri- 
tis groups were found to be significantly higher when compared with controls [18]

Also, these results were supported by the findings of Toker et al., who reported that IMA levels increased in patients with ARF at the time of diagnosis are positively associated with increasing level of inflammation. Also, serum IMA levels could be used as a follow-up marker just like acute inflammatory reactants for evaluating the efficacy of treatment in ARF [19].

The pathogenesis of rheumatic valvular disease has been responsible for fibrosis that occurs at the end of the inflammatory process. Furthermore, the oxidative stress increases in inflammatory disease. In addition, previous studies have shown that oxidative stress has been found to increase in acute rheumatic fever and chronic rheumatic heart disease and it is also thought to have a role in the pathogenesis of rheumatic carditis [20,21].

Ischaemia-modified albumin is considered to be a biochemical marker for ischaemic conditions

Initially, ischaemia-modified albumin was shown to be the most promising biomarker for early detection of cardiac ischaemia [22]. However, in recent studies, it has been shown to increase in several chronic diseases such as diabetes mellitus, chronic liver disease, end-stage renal failure, obesity, hypercholesterolaemia, and advanced cancer [23].Therefore, increased ischaemia-modified albumin does not only show cardiac ischaemia. In addition, chronic hypoxia, inflammation, and increased oxidative stress are considered to change the structure of albumin, and eventually elevation of the ischaemia modified albumin level occurs [24].On the other hand, despite the fact that pathologic evidence of myocardial inflammation has been shown in acute rheumatic carditis, the fact that the level of cardiac troponin-I is not elevated in acute rheumatic carditis suggests that there is minimal or no myocytic necrosis in this setting

The generation of reactive oxygen species can transiently modify the $\mathrm{N}$-terminal region of albumin and produce an increase in the concentration of ischaemia modified albumin [26] .

More recently, increased oxidative stress in patients with acute rheumatic fever compared with healthy controls has been reported [18]

Our results show that there was positive significant correlation between IMA level and the CRP, ASOT, ESR ( $1 \mathrm{st} \mathrm{h}$ and $2 \mathrm{nd})$ of patients.
These results were supported by the findings of Kaefer et al., who reported that there was positive correlation between ischaemia-modified albumin level and high sensitive C-reactive protein concentration in patients with type- 2 diabetes mellitus and hypercholesterolaemia has been reported in several studies [27]

These results were supported by the findings of Karatas et al., who reported that there was positive correlation between acute phase reactants and serum ischaemia-modified albumin levels [18]

And also, these results were supported by the findings of Toker et al., who reported that there was positive correlation between acute phase reactants and serum ischaemia-modified albumin levels [19].

Our results showed that there was significant increase of IMA level in patients with blood group $\mathrm{A}+$ with mean value $265.400 \mathrm{pg} / \mathrm{ml}$.

Our results also revealed that there was positive significant correlation between IMA level and the age of the patients due to increase the rate of URTI in agreement with [28].

We found by screening of families siblings of typical group that five siblings from ten had organic heart diseases, (two of five had active rheumatic heart diseases and other three siblings had chronic heart diseases). There was no significant increase of IMA in siblings who had chronic rheumatic heart dieases but there was significant increase of IMA in siblings who had active rheumatic disease with mean $(196.2 \mathrm{pg} / \mathrm{ml})$.

In atypical group, we found that two siblings had organic heart diseases and two had typical rheumatic arthritis from ten siblings, and there was no significant increase of IMA and acute phase reactants in these siblings as they had chronic rheumatic disease not active disease.

These results were supported by Karatas et al., [18] who reported that serum ischaemia-modified albumin and acute phase reactant levels of the patients with chronic rheumatic heart disease have been detected to be normal, although higher serum ischaemia-modified albumin and acute phase reactants levels have been demonstrated in patients with acute rheumatic fever.

The benefit of our study is "Early detection of RF in siblings of a case of RF with early management and prevention of RHD depending on positive family history of RF and elevating serum IMA". 


\section{Conclusion:}

Our study concluded that serum IMA level and ASOT increased in children with ARF/RHD as well as their siblings which facilitate early detection and management of RF in siblings of a case of RF depending on positive family history and elevating anti-streptococcal antibodies and serum Ischemia modified albumin.

\section{Recommendations:}

Early detection of RF in siblings of a case of RF with early management and prevention of RHD depending on positive family history and elevating anti-streptococcal antibodies and serum ischemia modified albumin.

\section{References}

1- CARAPETIS J.R., STEER A.C., MULHOLLAND E.K., et al.: The global burden of group A streptococcal diseases. Lancet Infect Dis., 5 (11): 68594, 2005.

2- SHULMAN S.T., BISNO A.L., CLEGG H.W., et al.: Clinical practice guideline for the diagnosis and management of group A streptococcal pharyngitis: 2012 update by the Infectious Diseases Society of America. Clinical Infectious Diseases, 55 (10): pp. e86-e102, 2012.

3- LENNON D., WILSON N. and ATATOA C.P.: Rheumatic fever diagnosis, management, and secondary prevention: a New Zealand guideline. N Z Med J., 121 (1271): 5969, 2008.

4- KUMAR R.K. and TANDON R.: Rheumatic fever \& rheumatic heart disease: The last 50 years. The Indian Journal of Medical Research, 137 (4): p. 643, 2013.

5- NELSON B., AYOUB E.M., SHULMAN S.T., et al.: Group A Streptococcal antibodies in subjects with or without rheumatic fever in areas with high or low incidences of rheumatic fever. Clin. Diagn. Lab. Immunol., 10: 886-890, 2003

6- AHMED M.I., GLADDEN J.D., LITOVSKY S.H., et al.: Increased oxidative stress and cardiomyocyte myofibrillar degeneration in patients with chronic isolated mitral regurgitation and ejection fraction $>60 \%$. Journal of the American College of Cardiology, 55 (7): pp. 671-679, 2010.

7- BEAUDOIN A., EDISON L., INTROCASO C.E., et al.: Acute rheumatic fever and rheumatic heart disease among children American Samoa, 2011-2012. MMWR. Morbidity and mortality weekly report, 64 (20): p. 555, 2015.

8- GEWITZ M.H., BALTIMORE R.S., TANI L.Y., et al.; Revision of the Jones Criteria for the diagnosis of acute rheumatic fever in the era of Doppler echocardiography: A scientific statement from the American Heart Association. Circulation, 131 (20): pp. 1806-1818, 2015.

9- SHETTY A. and VITUS D.S.: The utility of a single anti streptolysin o titer in the diagnosis of acute rheumatic fever. Journal of Evolution of Medical and Dental Sciences, Vol. 3, Issue 30, Page. 72-83, 2014.

10- SHOHEIB S.: A new classification of the syndrome of acute rheumatic fever. J. Arab Child 4: 1, 1994.
11- LAWRENCE J.G., CARAPETIS J.R., GRIFFITHS K., et al.: Acute rheumatic fever and rheumatic heart disease: Incidence and progression in the Northern Territory of Australia, 1997 to 2010. Circulation, 128: 492, 2013.

12- SHOHEIB S., ABDEL-FATTAH M., ZOAIR A., et al.: ABO-blood groups as a marker of RF/RHD susceptibility among siblings of families with a case of RHD. The Journal of Pediatric Club, 9: 78, 2009.

13- CARAPETIS J.R. (2004): Acute rheumatic fever. In: Warrell D.A., Cox T.M., Firth J.D., Benz E.J.J., eds. Oxford textbook of medicine, 4th edn. Oxford: Oxford University Press, 1050-56.

14- RAYAMAJHI A., SHARMA D. and SHAKYA U.: Clinical, laboratory and echocardiographic profile of acute rheumatic fever in Nepali children. An. Trop. Pediatr., 27 (3): 169-77, 2007.

15-REITZENSTEIN J.E., YAMAMOTO L.G. and MAVOOR H.: Similar erythrocyte sedimentation rate and C-reactive protein sensitivities at the onset of septic arthritis, osteomyelitis, acute rheumatic fever. Pediatr. Rep., 2 (1): e10, 2010.

16- IDRESS F.I. and AL QAHTANI M.T.: Extreme elevation of the erythrocyte sedimentation rate in children. Ann. Saudi Med., 27(3): 175-178, 2007.

17-BEN-CHETRIT E., MOSES A.E., AGMON-LEVIN N., et al.: Serum levels of anti-streptolysin $\mathrm{O}$ antibodies: Their role in evaluating rheumatic diseases. International Journal of Rheumatic Diseases, 15 (1): pp.78-85, 2012.

18- KARATAS Z., BAYSAL T., S AP F., et al.: Increased ischaemia-modified albumin is associated with inflammation in acute rheumatic fever. Cardiology in the Young, 24 (3): pp. 430-436, 2014.

19- TOKER A., KARATAS Z., ALT1N H., et al.: Evaluation of serum ischemia modified albumin levels in acute rheumatic fever before and after therapy. The Indian Journal of Pediatrics, 81 (2): pp. 120-125, 2014.

20- Uner A., Sal E., Dog an M., et al.: Investigation of oxidant and antioxidant pathway changes in acute rheumatic fever. Acta cardiologica, 65 (1): pp. 53-57, 2010.

21- OZAYDIN M., TURKER Y., VAROL E., et al.: Factors associated with the development of atrial fibrillation in patients with rheumatic mitral stenosis. The International Journal of Cardiovascular Imaging, 26 (5): pp. 547-552, 2010.

22- GURUMURTHY P., BORRA S.K., YERUVA R.K.R., et al.: Estimation of ischemia modified albumin (IMA) levels in patients with acute coronary syndrome. Indian Journal of Clinical Biochemistry, 29 (3): pp. 367-371, 2014.

23- ELLIDAG H.Y., BULBULLER N., EREN E., et al.: Ischemia-modified albumin: Could it be a new oxidative stress biomarker for colorectal carcinoma. Gut and Liver, 7 (6): p. 675, 2013.

24- SBAROUNI E., GEORGIADOU P. and VOUDRIS V.: Ischemia modified albumin changes-review and clinical implications. Clinical Chemistry and Laboratory Medicine, 49 (2): pp. 177-184, 2011.

25- OZDEMIR O., OGUZ D., ATMACA E., et al.: Cardiac troponin $\mathrm{T}$ in children with acute rheumatic carditis. Pediatric Cardiology, 32 (1): pp. 55-58, 2011. 
26- FANALI G., Di MASI A., TREZZA V., et al.: Human serum albumin: from bench to bedside. Molecular Aspects of Medicine, 33 (3): pp. 209-290, 2012.

27- KAEFER M., PIVA S.J., De CARVALHO J.A., et al.: Association between ischemia modified albumin, inflammation and hyperglycemia in type 2 diabetes mel- litus. Clinical Biochemistry, 43 (4-5): pp. 450-454 2010.

28- KAPLAN E.L., ROTHERMEL C.D. and JOHNSON D.R.: Antistreptolysin $\mathrm{O}$ and anti-deoxyribonuclease B titers: normal values for children ages 2 to 12 in the United States. Pediatrics, 101(1 Pt 1): 86-8, 1998.

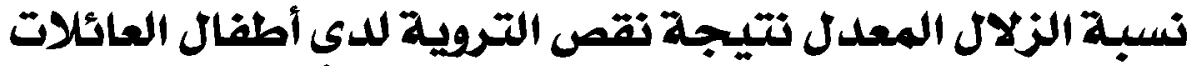

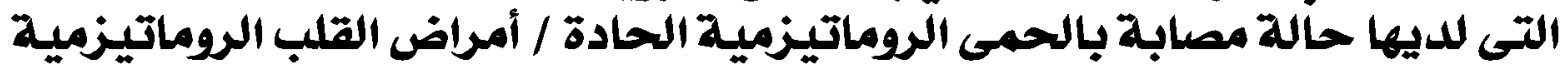

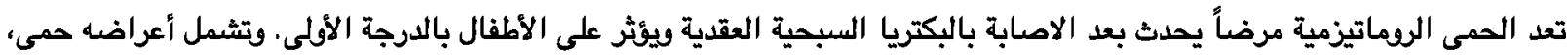

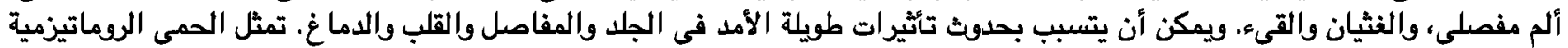

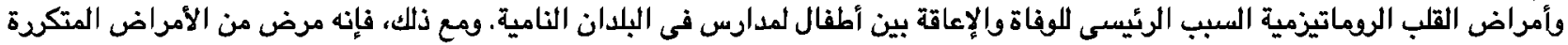

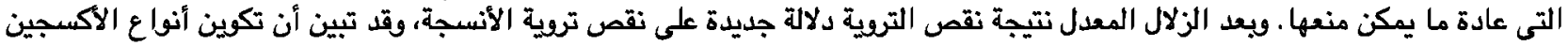

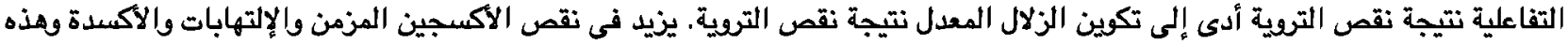

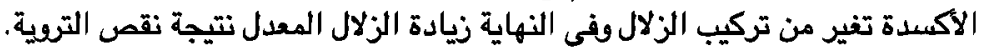

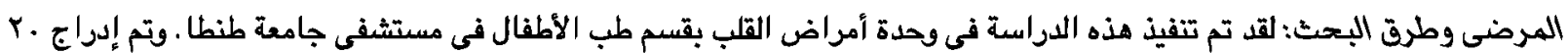
عائلة فى الدراسة التى تم تقسيمها إلى ثُلاث مجموعات بيذهما ترابط في العى العمر والجنس.

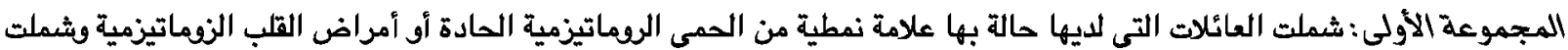

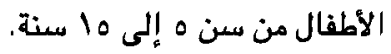

المجموعة الثانية: شملت العائلات التى لديها حالة بها علامة غير نمطية من الحمى الروماتيزمية الحادة أو أمراض القلب الزوماتيزمية وشملت الأطفال من سن ه إلى شانى 10 سنة.

المجموعة الثالثة: شملت العائلات التى ليس لها ألى تاريخ مرضئ منى من الحمى الروماتيزمية أو بنسللين طويل المفعول قيدوا كمجموعة

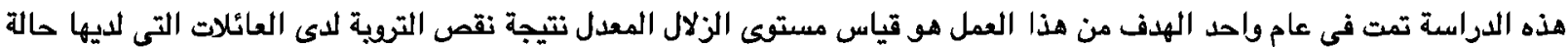
مصابة بالحمى الروماتيزمية الحادة / أمراض القلب الروماتيزمية أى كان الصورة التى التى يظهر بها.

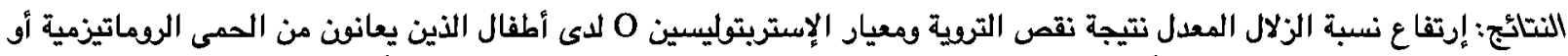

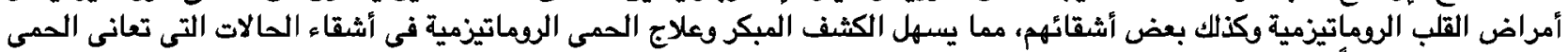

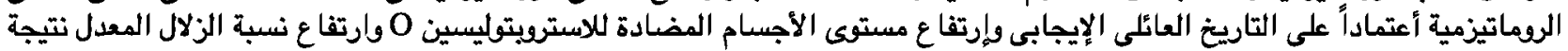
نقص التروية.

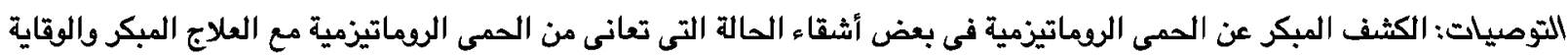

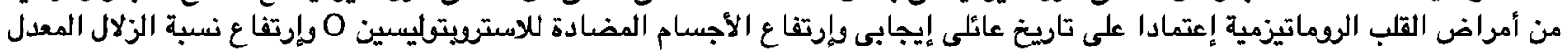
نتيجة نقص التروبة. 